\title{
(6) OPEN ACCESS \\ Injury risk in runners using standard or motion control shoes: a randomised controlled trial with participant and assessor blinding
}

\author{
Laurent Malisoux, ${ }^{1}$ Nicolas Chambon, ${ }^{2}$ Nicolas Delattre, ${ }^{2}$ Nils Gueguen, ${ }^{2}$ \\ Axel Urhausen, ${ }^{1,3}$ Daniel Theisen ${ }^{1}$
}

- Additional material is published online only. To view please visit the journal online (http://dx.doi.org/10.1136/ bjsports-2015-095031).

${ }^{1}$ Sports Medicine Research Laboratory, Luxembourg Institute of Health, Luxembourg, Luxembourg ${ }^{2}$ Decathlon, Movement Sciences Department, Villeneuve d'Ascq, France ${ }^{3}$ Sports Clinic, Centre Hospitalier de Luxembourg, Luxembourg, Luxembourg

\section{Correspondence to} Dr Laurent Malisoux, Sports Medicine Research Laboratory, Luxembourg Institute of Health, 76 rue d'Eich, Luxembourg, L-1460 Luxembourg; laurent. malisoux@lih.lu

Accepted 16 November 2015 Published Online First 8 January 2016

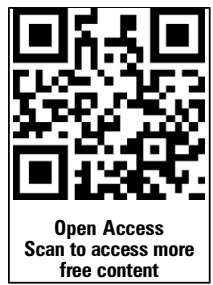

CrossMark

To cite: Malisoux $\mathrm{L}$, Chambon N, Delattre N, et al. Br J Sports Med 2016:50:481-487.

\section{ABSTRACT}

Background/aim This randomised controlled trial investigated if the usage of running shoes with a motion control system modifies injury risk in regular leisure-time runners compared to standard shoes, and if this influence depends on foot morphology.

Methods Recreational runners $(n=372)$ were given either the motion control or the standard version of a regular running shoe model and were followed up for 6 months regarding running activity and injury. Foot morphology was analysed using the Foot Posture Index method. Cox regression analyses were used to compare injury risk between the two groups, based on HRs and their $95 \% \mathrm{Cls}$, controlling for potential confounders. Stratified analyses were conducted to evaluate the effect of motion control system in runners with supinated, neutral and pronated feet.

Results The overall injury risk was lower among the participants who had received motion control shoes ( $\mathrm{HR}=0.55 ; 95 \% \mathrm{Cl} 0.36$ to 0.85$)$ compared to those receiving standard shoes. This positive effect was only observed in the stratum of runners with pronated feet $(n=94 ; H R=0.34 ; 95 \% \mathrm{Cl} 0.13$ to 0.84$)$; there was no difference in runners with neutral $(n=218 ; H R=0.78$; $95 \% \mathrm{Cl} 0.44$ to 1.37$)$ or supinated feet $(n=60$; $\mathrm{HR}=0.59 ; 95 \% \mathrm{Cl} 0.20$ to 1.73). Runners with pronated feet using standard shoes had a higher injury risk compared to those with neutral feet $(\mathrm{HR}=1.80 ; 95 \% \mathrm{Cl}$ 1.01 to 3.22 ).

Conclusions The overall injury risk was lower in participants who had received motion control shoes. Based on secondary analysis, those with pronated feet may benefit most from this shoe type.

\section{INTRODUCTION}

Several hundred running shoe models are currently available in the market. Notwithstanding the increasing focus on running shoe design, technologies and function, running-related injury incidence has not changed noticeably over the last few decades. ${ }^{1}$ Various biomechanical variables such as strike pattern, ${ }^{2}$ impact forces, ${ }^{3}$ foot posture or foot pronation, ${ }^{45}$ have all been proposed as injury risk factors. Footwear features such as cushioning technology, stability and motion control systems (motion control shoes), have been designed to mitigate against these risk factors and are extensively used as selling points by shoe manufacturers.

Foot posture is believed by some to be a risk factor for injury. ${ }^{5}$ This often results in attempts to match footwear to a runner's foot morphology, despite an absence of evidence to suggest this approach will reduce injuries. ${ }^{4-6}$ Specifically, motion control shoes are typically prescribed to runners with pronated feet, while neutral stability shoes are recommended to individuals with neutral feet and cushioned shoes to those with supinated feet. Several studies have been unable to demonstrate the benefit of the above-described prescription strategy, ${ }^{7-10}$ although they were either inadequately powered, ${ }^{9}$ or performed in a military population, ${ }^{78}$ limiting the applicability of findings to distance runners. ${ }^{4}$ Furthermore, a more pronated foot posture was reported not to be associated with injury risk in a prospective cohort study on over 900 novice runners, ${ }^{11}$ questioning the use of running shoes featuring motion control systems designed to reduce foot pronation. Running in shoes equipped with that technology increased the risk of experiencing running-related pain. ${ }^{9}$ Although these results are preliminary, it is worrying that a significant proportion of running shoes have motion control, a fact that many runners may not be aware of when buying their shoes.

Therefore, in this study, we (1) investigated whether running shoes equipped with motion control features modified injury risk in regular leisure-time runners and (2) if this influence depended on foot morphology. Our main hypothesis was that injury risk would be different when running in shoes with motion control compared with standard (neutral) shoes, while controlling for the potential confounders. Our secondary hypothesis was that the difference in injury risk would depend on foot morphology.

\section{MATERIALS AND METHODS}

\section{Participants and study design}

This randomised controlled trial (unregistered) recruited recreational runners, regardless of fitness level. Reporting of the study followed the CONSORT statement. ${ }^{12}$ Given an expected injury rate of $22 \%$ and $35 \%$ in the two groups, ${ }^{9}$ respectively, and a desired power of 0.8 and an $\alpha$-level of 0.05 , a total of 364 runners were required to test our main hypothesis. All participants received a full description of the study protocol and provided written informed consent for participation. All procedures were approved by the National Ethics Committee for Research (ref 201211/04). Participants were recruited via advertisements in local newspapers and on specialised internet sites from March to April 2014. Following online registration, participants were contacted by phone to verify inclusion criteria: healthy, aged 18-65 years, 
regular running (at least 1 session/week) for at least 6 months over the 12 months prior to the study, no contraindication to perform running activity, no prior $(<12$ months) surgery at the lower limbs or lower back region, and no use of orthopaedic insoles for running activities. Volunteers were also required to perform at least one running activity per week during the 6-month follow-up period (from June to December), to use the provided study shoes for all running activities, and to report, at least once per week, all sports activities and injury or pain experienced during the follow-up.

Individuals reported to the laboratory for eligibility check and baseline assessment. A questionnaire gathered information about age, sex, running regularity over the previous 12 months (months of practice), running experience (years of regular practice) and previous injury to the lower back or lower limbs preventing normal running activity during the preceding 12 months. Foot posture was assessed using the six-item Foot Posture Index (FPI), previously proven to be valid. ${ }^{13} 14$ Normative values presented by Redmond et $a l^{15}$ were used as references to categorise each foot into one of the five categories (highly supinated, supinated, neutral, pronated and highly pronated) based on their FPI score. Two previously trained appraisers performed all evaluations and assessed the first 50 participants together to optimise consistency. Subsequently, high inter-rater agreement for classifying the runners in one of the five categories was found based on a further 40 participants, with a Cohen's $\kappa$ coefficient of 0.86 . Since the unit of analysis is the participant, the classification into one of the five categories was based on the foot with the most extreme score.

\section{Study shoes characteristics}

Two versions (motion control and standard) of a running shoe model were provided for the trial by a renowned sport equipment manufacturer. Shoes were de-identified so the study participants did not know which brand they were given. The motion control shoes and standard shoes both had a heel-to-toe drop of $10 \mathrm{~mm}$ and were derived from a commercially available model. Motion control shoes were characterised by (1) a thermoplastic polyurethane structure located at the medial part of the midfoot and (2) a dual-density ethyl-vinyl-acetate (EVA) midsole located at the forefoot (figure 1). Apart from these features, the two versions were identical, so participants did not know which type of shoe they used.

A subset of each version was characterised regarding midsole hardness difference between the medial and the lateral part of the midsole, using an Asker-C durometer according to the standard JIS K 7312 protocol for hardness characterisation of viscoelastic polymers (average value of 5 independent measures/ shoe; 12 shoes tested/model). The measure was taken perpendicularly to the frontal plan, with the shoes cut at the level of the first metatarsal head.

Participants were randomly allocated to one of the two shoe models in accordance with stratification by potential confounders (age and body mass index (BMI); cut-off values are medians) ${ }^{16}$ and foot morphology. Participants and assessors involved in the shoe distribution and participant follow-up were both blinded regarding the shoe allocation. Each shoe pair was coded by a coworker not involved in the study prior to the distribution. The code was broken after completion of data collection.

\section{Data collection during follow-up}

A dedicated internet-based platform (http://www.tipps.lu, Training and Injury Prevention Platform for Sports) was used to collect all information of the participants pertaining to their sports participation and any adverse events (injuries, pains and illnesses). ${ }^{17-19}$ Training sessions were characterised by the type of activity, context, duration, subjectively perceived intensity measured using the Borg CR-10 scale, ${ }^{20}$ distance covered, running surface and shoes worn. Whether participants experienced any pain during the session forcing him/her to reduce volume or intensity, or to interrupt the practice, was also reported. The response to each item was mandatory for every declared training session or competition and could be selected from a predefined list.

Injury was self-reported and defined as any physical pain located at the lower limbs or lower back region, sustained during or as a result of running practice, and impeding planned running activity for at least 1 day (time-loss definition). The online injury questionnaire has been previously described. ${ }^{21}$ Injuries were classified according to consensus guidelines on sports injury surveillance studies. ${ }^{22} 23$

Self-reported data on every injury were systematically checked by the principle investigator for completeness and coherence. Participants who did not complete their entire running calendar with weekly information were contacted by one of the investigators to ensure that injury was not the reason for noncompliance. A participant was considered as dropping out of the study when no data had been uploaded in the system for more than 2 weeks despite an automatic email reminder and a phone call from the research team. At the end of the study (December 2014), the participants were invited for a final visit to check all injury data, compliance and shoe use.

\section{Statistical analyses}

Descriptive data for the shoe properties, as well as the personal and training-related characteristics are presented as count and percentage for dichotomous variables, and as mean and SD, or as median and range, respectively, for normally and abnormally distributed continuous variables. Average sport-related characteristics were computed for each participant over their specific period of observation. Lateral and medial midsole densities of both models were analysed using a Student's t test.

To address the first objective, unadjusted Cox proportional hazard regressions were performed to present the crude estimates of hazard ration (HR) for shoe version and other potential risk factors. Date at inclusion (shoe distribution date) and date at injury or at censoring were basic data used to calculate the time at risk. A participant was right-censored, yet included in the analyses, in case of severe disease, non-injury causing a modification of the running plan or at the end of follow-up (shoe return date), whichever came first. Time at risk was expressed in hours spent running and used as the time scale. To validate the statistical model, the assumption of proportional hazards was evaluated by log-minus-log plots. The variables with a $\mathrm{p}$ value $<0.200$ were included in the adjusted Cox regression analysis to determine if the use of motion control shoes is associated with injury risk, regardless of runners' foot morphology, and controlling for potential confounders. The recommendation of using at least 10 injuries per predictor variable included in the Cox regression analysis was strictly followed. ${ }^{24}$

To address the second objective, a stratified analysis was performed to investigate the interaction between shoe version and foot morphology. HRs and their 95\% CIs were determined for different foot morphology strata, with a single reference category (the stratum of runners with neutral feet, using neutral shoes). ${ }^{25}{ }^{26} \mathrm{HR}$ and the corresponding 95\% CI were computed within strata of foot type to determine the effect of the shoe 
Figure 1 Illustration of the two technical features (coloured in black limit the pronation movement of the runners. (A) Represents a piece of rigid plastic (thermoplastic polyurethane) located on the medial side, under the midfoot at the midsole edge. (B) Area of the harder midsole EVA (ethylene-vinyl acetate) foam. These elements were not recognisable on the shoe version distributed. for illustration purposes) designed to
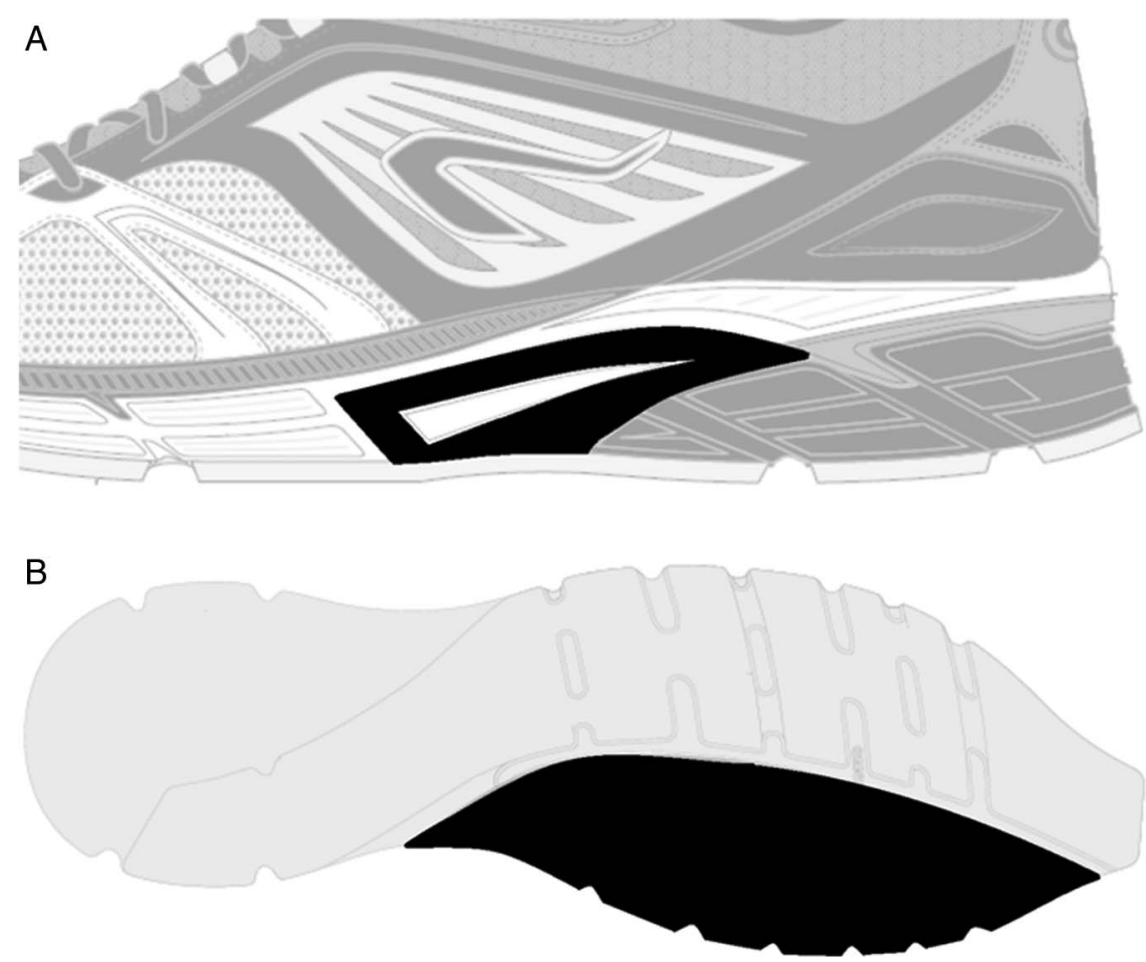

model within each strata. Significance was accepted for $\mathrm{p}<0.05$. All analyses were performed using SPSS V.20.

\section{RESULTS}

\section{Participants}

A total of 423 eligible volunteers came to the laboratory for the initial visit and shoe order. Thirty-seven participants did not retrieve their running shoes because of injuries $(n=11)$ or other health problems $(n=5)$ during the production period, lack of interest to participate $(n=17)$ or withdrawal for personal reasons $(n=4)$. A total of 386 pairs of running shoes were thus distributed. After shoe distribution, 14 participants were excluded from the analysis because they did not upload any training data $(n=8)$, had not used the study shoes for more than 2 sessions $(n=5)$ or had health problems unrelated to running $(n=1)$. In total, 51 participants (figure 2$)$ with similar demographics and foot type distribution to those of the final sample were excluded from the analyses (see online supplementary table S1).

A total of 12558 running sessions were recorded for a distance of $116723 \mathrm{~km}$ and $12094 \mathrm{~h}$ run. Table 1 illustrates the characteristics of the two study groups, which both had a high compliance regarding the use of the provided study shoes. The average data uploading delay was 4 days. Since there were few participants with hyperpronated and hypersupinated feet, these categories were merged with those of pronated and supinated feet, respectively.

\section{Shoe characteristics}

In motion control shoes, the midsole hardness was 15\% higher $(\mathrm{p}<0.001)$ in the medial part compared to the lateral part (Asker $C$ values $60 \pm 2$ and $51 \pm 2$, respectively), while there was no difference in standard shoes (51 \pm 3 and $51 \pm 2$, respectively).

\section{Injuries}

An injury was sustained by 93 participants (25\%) during the follow-up. The overall incidence was 7.69 injuries $/ 1000 \mathrm{~h}$ of exposure (95\% CI 6.28 to 9.41 ). There were $32.4 \%$ of participants injured in the standard shoe group and $17.6 \%$ in the motion control shoe group ( $R R=0.54,95 \%$ CI 0.37 to 0.79 ). More details on the first-time injury characteristics are presented in table 2.

\section{Primary analysis}

Overall, the injury risk was lower among the participants who had received motion control shoes $(p=0.005$; table 3$)$. Both the unadjusted and the adjusted model revealed that previous injury was a risk factor $(\mathrm{p}<0.001)$. Additionally, BMI, running regularity and mean session distance were associated with injury risk, but only in the unadjusted model. Both models yielded very similar estimates for the shoe version. Thus, crude estimates were used in the secondary analyses.

\section{Secondary analysis}

In the subgroup of runners with pronated feet $(n=94)$, the rate at which the injuries occurred was significantly lower among the participants using the motion control shoes $(\mathrm{HR}=0.34 ; 95 \% \mathrm{CI}$ observed in runners with neutral $(\mathrm{HR}=0.78 ; 95 \% \mathrm{CI} 0.44$ to $1.37)$ or supinated feet $(\mathrm{HR}=0.59 ; 95 \% \mathrm{CI} 0.20$ to 1.73$)$. No difference was found between the strata regarding the principle confounders (see online supplementary table S2). Interestingly, among the participants who received standard shoes, the rate at which the injuries occurred was significantly higher in the group of runners with pronated feet compared to runners with neutral feet $(\mathrm{HR}=1.80,95 \% \mathrm{CI} 1.01$ to 3.22$)$. In the group of participants with pronated feet, 25 had one foot classified as neutral. A sensitivity analysis showed that reclassifying these runners into the group with neutral feet did not affect the results.

\section{DISCUSSION}

This is the first large-scale prospective cohort study to investigate the effectiveness of motion control shoes on injury risk among regular leisure-time runners. We found that running in shoes with 0.13 to 0.84 ; bottom line of table 4 ). This difference was not 


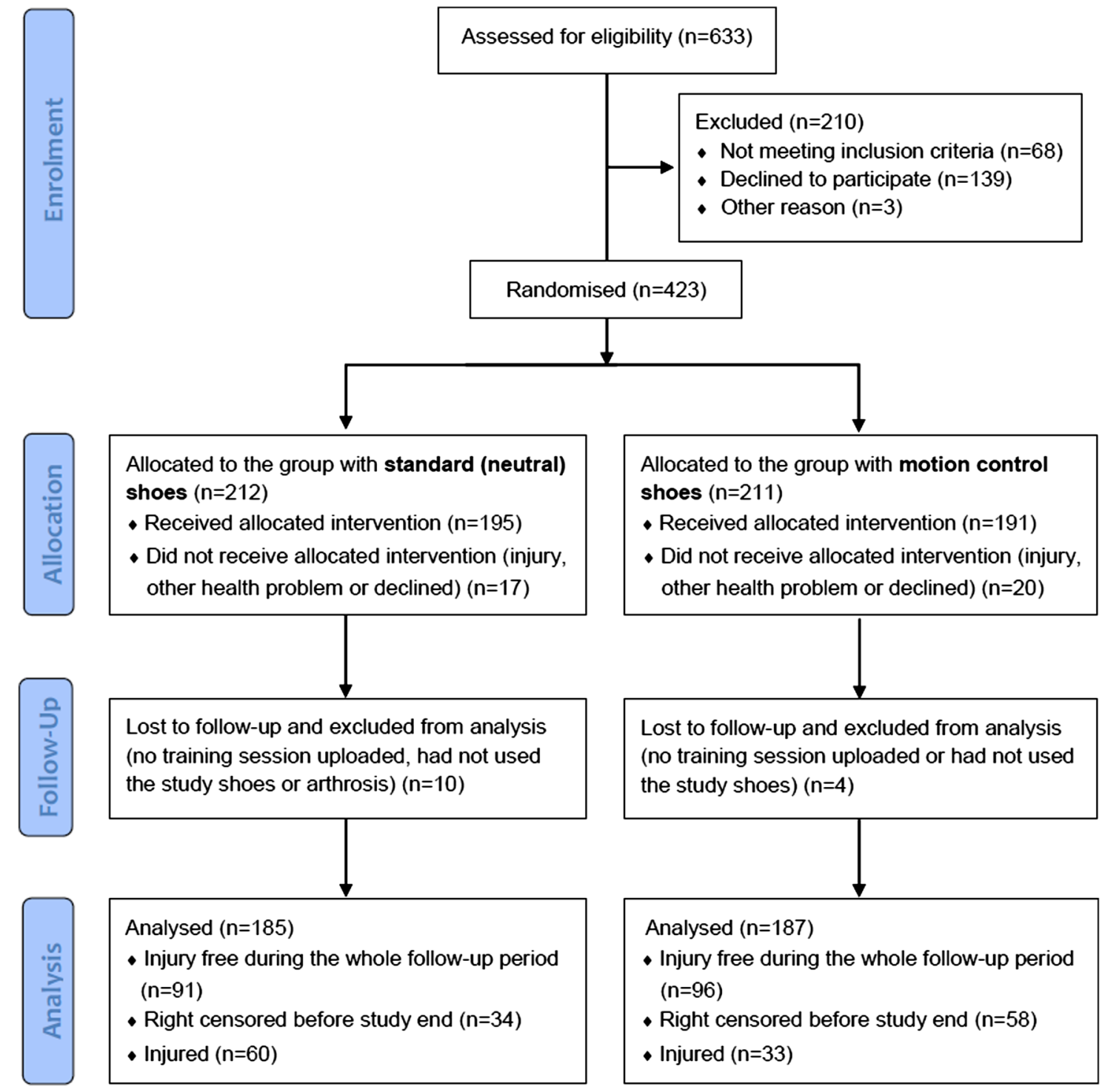

Figure 2 Flow chart of volunteers and study participants.

motion control was associated with a significantly lower overall injury risk, thus confirming our main hypothesis. However, in accordance with our secondary hypothesis, this general protective effect of motion control shoes was demonstrated only in runners with pronated feet, while those with neutral or supinated feet did not benefit from this technology. In addition, the stratified analysis revealed that, among the runners who received the standard shoes, those with pronated feet had a higher injury risk than those with neutral feet (table 4). Nevertheless, these secondary findings must be viewed as preliminary and need to be verified by further research including a larger sample size.

\section{Matching running shoes to foot type?}

The injury incidence reported in the present study (7.7 injuries/ $1000 \mathrm{~h}$ of running) was consistent with previous results from our laboratory and a meta-analysis (6.7 and 7.7 RRI/1000 h, respectively). ${ }^{26} 27$ The influence of shoe technology on injury risk in our study may appear inconsistent with some prior research. However, differences in study design, population and shoe characteristics must be considered. Previous studies in military populations ${ }^{6-8}$ and female runners ${ }^{9}$ have investigated the effectiveness of matching running shoes according to foot shape, but none found evidence for pronating runners to be advised to wear antipronation shoes.

Importantly, however, the study series by Knapik et $a l^{6-8}$ focused on military populations where recruits are exposed to high training loads during activities other than running, meaning findings may not necessarily be extrapolated to recreational runners. The study by Ryan et $a l^{9}$ involving female runners analysed the effect of three levels of footwear stability on pain outcomes. However, the participants were not blinded and their final sample size was small $(n=81)$. Additionally, the study groups were not equivalent regarding body mass and running experience, two potential confounders. Furthermore, the 'neutral' running shoe used in their study (Pegasus, Nike) actually possesses motion control features, including a thermoplastic midfoot shank and a lateral sole flare. This illustrates that shoes from different brands presented as neutral may not be identical, and that care must be taken when drawing conclusions from studies that have used different shoe models.

A large prospective cohort study (DANORUN) in novice runners using neutral shoes previously questioned the belief that a pronated foot posture is a risk factor for injury. ${ }^{11}$ Indeed, that study revealed that runners with pronated feet were at a similar risk of injury compared to those with neutral feet. Contrastingly, 
Table 1 Participants' characteristics and sport participation pattern for both study groups

\begin{tabular}{|c|c|c|c|}
\hline Characteristics & Unit/qualifier & $\begin{array}{l}\text { Standard } \\
\text { shoes } \\
(n=185)\end{array}$ & $\begin{array}{l}\text { Motion } \\
\text { control } \\
\text { shoes } \\
(n=187)\end{array}$ \\
\hline \multicolumn{4}{|l|}{ Participants' characteristics } \\
\hline Age & Years & $41.0 \pm 11.2$ & $39.9 \pm 9.7$ \\
\hline \multirow[t]{2}{*}{ Sex } & Male & $113(61 \%)$ & $111(59 \%)$ \\
\hline & Female & 72 (39\%) & $76(41 \%)$ \\
\hline BMI & $\mathrm{kg} / \mathrm{m}^{2}$ & $23.7 \pm 3.0$ & $23.6 \pm 3.1$ \\
\hline \multirow[t]{2}{*}{ Previous injury } & Yes & $137(74.1 \%)$ & $143(76.5 \%)$ \\
\hline & No & $48(25.9 \%)$ & $44(23.5 \%)$ \\
\hline Running experience & Years & $7[0-45]$ & $5[0-37]$ \\
\hline $\begin{array}{l}\text { Regularity } \\
\text { (last } 12 \text { months) }\end{array}$ & Months & 12 [6-12] & 12 [3-12] \\
\hline \multirow[t]{5}{*}{ Foot morphology } & Hypersupinated & $5(2.7 \%)$ & $5(2.7 \%)$ \\
\hline & Supinated & $25(13.5 \%)$ & $25(13.4 \%)$ \\
\hline & Neutral & $108(58.4 \%)$ & $110(58.8 \%)$ \\
\hline & Pronated & $39(21.1 \%)$ & $41(21.9 \%)$ \\
\hline & Hyperpronated & $8(4.3 \%)$ & $6(3.2 \%)$ \\
\hline \multicolumn{4}{|l|}{ Sport participation pattern } \\
\hline $\begin{array}{l}\text { Sessions run with study } \\
\text { shoes }\end{array}$ & $\begin{array}{l}\% \text { of total } \\
\text { sessions }\end{array}$ & $95.1 \pm 11.8$ & $94.9 \pm 10.6$ \\
\hline Other sports & Sessions/week & $1.0 \pm 1.5$ & $0.9 \pm 1.3$ \\
\hline Running frequency & Sessions/week & $1.9 \pm 0.9$ & $1.9 \pm 1.3$ \\
\hline Mean session duration & $\min$ & $56 \pm 15$ & $57 \pm 43$ \\
\hline Mean session distance & $\mathrm{km}$ & $9.0 \pm 2.6$ & $8.7 \pm 3.4$ \\
\hline Mean session intensity & $\mathrm{au}$ & $3.8 \pm 1.0$ & $3.7 \pm 1.0$ \\
\hline Mean speed & $\mathrm{Km} / \mathrm{h}$ & $9.7 \pm 1.2$ & $9.6 \pm 1.4$ \\
\hline Runs on hard surface & $\begin{array}{l}\% \text { of total } \\
\text { sessions }\end{array}$ & $60.4 \pm 31.2$ & $58.3 \pm 33.6$ \\
\hline Competition & $\begin{array}{l}\% \text { of total } \\
\text { volume }\end{array}$ & $1.9 \pm 3.4$ & $2.4 \pm 7.8$ \\
\hline
\end{tabular}

au, arbitrary unit; BMI, body mass index.
Table 2 Characteristics of self-reported first-time running-related injuries for each study group $(n=93)$

\begin{tabular}{|c|c|c|c|c|}
\hline & \multicolumn{2}{|c|}{ Standard shoes } & \multicolumn{2}{|c|}{$\begin{array}{l}\text { Motion control } \\
\text { shoes }\end{array}$} \\
\hline & $\mathrm{N}$ & Per cent & $\mathrm{N}$ & Per cent \\
\hline \multicolumn{5}{|l|}{ Injury location } \\
\hline Lower back region/pelvis & 2 & 3.3 & 0 & 0 \\
\hline Hip/groin & 5 & 8.3 & 1 & 3 \\
\hline Thigh & 5 & 8.3 & 4 & 12.1 \\
\hline Knee & 10 & 16.7 & 7 & 21.2 \\
\hline Lower leg & 16 & 26.7 & 7 & 21.2 \\
\hline Ankle & 13 & 21.7 & 10 & 30.3 \\
\hline Foot & 8 & 13.3 & 4 & 12.1 \\
\hline Toe & 1 & 1.7 & 0 & 0 \\
\hline \multicolumn{5}{|l|}{ Injury type } \\
\hline Tendon & 25 & 41.7 & 17 & 51.5 \\
\hline Muscle & 18 & 30 & 9 & 27.3 \\
\hline Capsules and ligaments & 8 & 13.3 & 5 & 15.2 \\
\hline Bone structures & 5 & 8.3 & 1 & 3 \\
\hline Other joint structures & 2 & 3.3 & 1 & 3 \\
\hline Other injury/unknown & 2 & 3.4 & 0 & 0 \\
\hline \multicolumn{5}{|l|}{ Injury severity } \\
\hline Slight (0-3 days) & 16 & 26.7 & 7 & 21.2 \\
\hline Minor (4-7 days) & 4 & 6.7 & 8 & 24.2 \\
\hline Moderate (8-28 days) & 25 & 41.7 & 12 & 36.4 \\
\hline Major (>28 days) & 15 & 25 & 6 & 18.2 \\
\hline \multicolumn{5}{|l|}{ Recurrence } \\
\hline No & 32 & 53.3 & 22 & 66.7 \\
\hline Yes & 28 & 46.7 & 11 & 33.3 \\
\hline \multicolumn{5}{|l|}{ Injury category } \\
\hline Acute & 13 & 21.7 & 8 & 24.2 \\
\hline Progressive & 47 & 78.3 & 25 & 75.8 \\
\hline
\end{tabular}

Self-reported injuries were classified according to consensus guidelines for sports injury surveillance studies. ${ }^{21} 22$ we observed a higher injury risk in our subgroup possessing a more pronated foot posture. However, our target population (more experienced and regular runners) and shoe brand used were different. Since the DANORUN and the present study are currently the only ones to investigate the association between foot morphology and injury risk, further research is required to explain this apparent discrepancy and to reach a final conclusion.

\section{Clinical implications}

Runners have used cushioned shoes for only four decades, which contrasts with the long-term anatomical and neuromotor adaptations brought about by millions of years while running barefoot or in minimal footwear. ${ }^{3}$ One of the main characteristics of modern shoes is their cushioning properties aiming to increase the comfort and decrease the impact force at touchdown. ${ }^{28}$ However, the softer the sole of the shoe, the greater the risk of overpronation movement. ${ }^{29} \mathrm{~A}$ previous study already suggested that a certain degree of additional stability may be beneficial even for those individuals with neutral foot posture. ${ }^{9}$ This could be especially true for shoes with soft midsoles. The shoes used in the present study had an overall stiffness that was probably located within the lower $10-15 \%$ range of commonly available models, according to data from Shorten and Mientjes ${ }^{30}$ and those from our previous study. ${ }^{18}$

One might speculate that runners with pronated feet were insufficiently stabilised with the current standard shoe version and that additional motion control could be achieved with the motion control shoe version. The fact that motion control shoes are effective in controlling foot pronation, especially footwear with dual midsole materials used in this study, ${ }^{31}$ supports this argument. We observed that runners with pronated feet were protected when running in motion control shoes and that they were exposed to a greater injury risk when using the standard shoes. Unfortunately, in the absence of biomechanical data, the mechanisms involved in the injuries observed in our study are unclear. Future research should investigate what degree of motion control is needed in our modern cushioned shoes with regard to foot morphology and other footwear properties.

\section{Strengths and limitations}

Strengths of this study include the randomised controlled design with participant and assessor blinding, a stratified randomisation and a prospective follow-up over 6 months, plus the fact that the two running shoe versions were strictly similar except for the motion control features. A major 
Table 3 Results of the unadjusted and adjusted Cox regression models for the variables tested

\begin{tabular}{|c|c|c|c|c|c|c|}
\hline \multirow{2}{*}{ Indicator } & \multirow[b]{2}{*}{ Unit/qualifier } & \multicolumn{3}{|c|}{ Unadjusted model } & \multicolumn{2}{|c|}{ Adjusted model } \\
\hline & & HR & $95 \% \mathrm{Cl}$ & p Value & HR & $95 \% \mathrm{Cl}$ \\
\hline \multicolumn{7}{|l|}{ Main exposure of interest } \\
\hline Shoe version & Standard shoes is ref & $0.59^{*}$ & 0.39 to 0.91 & $0.016 \dagger$ & $0.55^{*}$ & 0.36 to 0.85 \\
\hline \multicolumn{7}{|l|}{ Participants' characteristics } \\
\hline Age & Years & 0.99 & 0.97 to 1.01 & $0.150 \dagger$ & 0.99 & 0.97 to 1.02 \\
\hline Sex & Male is ref & 1.02 & 0.67 to 1.54 & 0.944 & & \\
\hline BMI & $1 \mathrm{~kg} / \mathrm{m}^{2}$ increase & $1.07^{*}$ & 1.01 to 1.15 & $0.034 \dagger$ & 1.05 & 0.98 to 1.12 \\
\hline Previous injury & No (previous injury) is ref & $2.77^{*}$ & 1.82 to 4.21 & $<0.001 \dagger$ & $2.70^{*}$ & 1.77 to 4.11 \\
\hline Running experience & Years & 0.99 & 0.97 to 1.02 & 0.527 & & \\
\hline Regularity (last 12 months) & Months & $0.90^{*}$ & 0.82 to 0.99 & $0.028+$ & 0.91 & 0.83 to 1.01 \\
\hline \multirow[t]{3}{*}{ Foot morphology } & Neutral is ref & & & & & \\
\hline & Supinated (and highly) & 1.27 & 0.72 to 2.24 & $0.405 \dagger$ & 1.42 & 0.80 to 2.54 \\
\hline & Pronated (and highly) & 1.34 & 0.84 to 2.15 & $0.225 \dagger$ & 1.43 & 0.88 to 2.30 \\
\hline \multicolumn{7}{|l|}{ Sport participation pattern } \\
\hline Other sports frequency & Sessions/week & 1.04 & 0.91 to 1.18 & 0.617 & & \\
\hline Running frequency & Sessions/week & 0.78 & 0.61 to 1.01 & $0.057 \dagger$ & 0.82 & 0.62 to 1.08 \\
\hline Mean session duration & $\min$ & 1.00 & 0.99 to 1.01 & 0.974 & & \\
\hline Mean session distance & $\mathrm{km}$ & $0.90^{*}$ & 0.83 to 0.98 & $0.014 \dagger$ & 0.93 & 0.86 to 1.02 \\
\hline Mean session intensity & au & 0.91 & 0.73 to 1.14 & 0.424 & & \\
\hline
\end{tabular}

*Significant results.

†Variables with $\mathrm{p}$ value $<0.200$ or used for the stratified randomisation were included in the adjusted model; total volume of exposure: $12094 \mathrm{~h}$; au, arbitrary unit; BMI, body mass index.

$\ddagger$ Years of regular practice of running.

Table 4 Stratified analysis of the effect of shoe version according to foot morphology $(n=372)$

\begin{tabular}{|c|c|c|c|}
\hline & $\begin{array}{l}\text { Supinated feet } \\
\text { Injured/non-injured } \\
\text { HR }(95 \% \mathrm{Cl}) \\
\text { p value }\end{array}$ & $\begin{array}{l}\text { Neutral feet } \\
\text { Injured/non-injured } \\
\text { HR }(95 \% \mathrm{Cl}) \\
\text { p value }\end{array}$ & $\begin{array}{l}\text { Pronated feet } \\
\text { Injured/non-injured } \\
\text { HR }(95 \% \mathrm{Cl}) \\
\mathrm{p} \text { value }\end{array}$ \\
\hline Standard shoes & $\begin{array}{l}11 / 19 \\
1.49(0.74 \text { to } 2.98) \\
0.263\end{array}$ & $\begin{array}{l}30 / 78 \\
1\end{array}$ & $\begin{array}{l}19 / 28 \\
\left.1.80^{*} \text { (1.01 to } 3.22\right) \\
0.048\end{array}$ \\
\hline Motion control shoes & $\begin{array}{l}5 / 25 \\
0.76(0.29 \text { to } 1.97) \\
0.574\end{array}$ & $\begin{array}{l}21 / 89 \\
0.79(0.45 \text { to } 1.38) \\
0.398\end{array}$ & $\begin{array}{l}7 / 40 \\
0.64(0.28 \text { to } 1.45) \\
0.280\end{array}$ \\
\hline $\begin{array}{l}\text { HR }(95 \% \mathrm{Cl}) \text {; p value for shoe version within strata } \\
\text { of foot morphology (standard shoes is ref) }\end{array}$ & $\begin{array}{l}0.59(0.20 \text { to } 1.73) \\
0.335\end{array}$ & $\begin{array}{l}0.78(0.44 \text { to } 1.37) \\
0.382\end{array}$ & $\begin{array}{l}\left.0.34^{*} \text { ( } 0.13 \text { to } 0.84\right) \\
0.020\end{array}$ \\
\hline
\end{tabular}

*Significant results; the reference was the group of runners with neutral feet, using neutral shoes.

limitation is that too few runners with highly supinated or highly pronated feet participated in the study, thus not allowing analyses of these subgroups. Additionally, the absence of significant results for runners with supinated and neutral foot types may be due to the low sample size, since the study was not powered for these secondary analyses. This limitation is highlighted by the small number of events observed in the stratum of runners with supinated feet, indicating that these results should be considered with caution (table 4). Given that the participants were asked to use the study shoes for all their running sessions, those runners preferring to use more than one shoe pair may have been reluctant to register. Thus, the volunteers included in this study may not represent all recreational runners. Another aspect of this study is that only one shoe model was tested regarding the effect of motion control technology. Therefore, our results may not be generalisable to other shoe models or brands.

\section{Summary}

The overall injury risk was lower among the participants who had received motion control shoes. Based on secondary analysis, it appears that runners with pronated feet may benefit most from this shoe type.

\section{What are the new findings?}

- In recreational runners, the use of motion control shoes was associated with lower injury risk compared to standard shoes.

- Among the runners using standard shoes, those with pronated feet were at a higher risk of injury compared to those with neutral feet.

- Runners with pronated feet may benefit most from shoes with motion control. 


\section{How might it impact on clinical practice in the future?}

- With cushioned running shoes, some motion control may be necessary to limit injury risk in recreational runners.

- Recreational runners with pronated feet using neutral shoes may be at an increased risk of injury.

- Runners with pronated feet may be advised to try motion control shoes for running.

Acknowledgements The authors would like to thank Dr Stephen Senn for preparing the randomisation, and Mr Daniel Karels and Mrs Romy Primc for their precious assistance with data collection.

Contributors LM, NC, ND, NG, AU and DT contributed to the study conception and study design; LM was responsible for the acquisition and analysis of the data. NC was responsible for shoe testing. LM and DT were responsible for data interpretation and manuscript drafting. $L M, N C, N D, N G, A U$ and DT contributed to critical manuscript revision and approval. LM and DT were responsible for the overall content.

Funding This study was co-funded by Decathlon, Movement Sciences Department, Villeneuve d'Ascq, France.

Competing interests $A$ research partnership agreement was signed between Decathlon and the LIH. ND, NC and NG are employed at Decathlon Group.

Patient consent Obtained.

Ethics approval National Ethics Committee for Research (CNER; ref 201211/04).

Provenance and peer review Not commissioned; externally peer reviewed.

Open Access This is an Open Access article distributed in accordance with the Creative Commons Attribution Non Commercial (CC BY-NC 4.0) license, which permits others to distribute, remix, adapt, build upon this work non-commercially, and license their derivative works on different terms, provided the original work is properly cited and the use is non-commercial. See: http://creativecommons.org/ licenses/by-nc/4.0/

\section{REFERENCES}

1 Knapik JJ, Jones BH, Steelman RA. Physical training in boots and running shoes: a historical comparison of injury incidence in basic combat training. Mil Med 2015; 180:321-8.

2 Mann R, Malisoux L, Nuhrenborger C, et al. Association of previous injury and speed with running style and stride-to-stride fluctuations. Scand I Med Sci Sports 2015;25:e638-45.

3 Lieberman DE, Venkadesan M, Werbel WA, et al. Foot strike patterns and collision forces in habitually barefoot versus shod runners. Nature 2010;463:531-6.

4 Richards CE, Magin PJ, Callister R. Is your prescription of distance running shoes evidence-based? Br J Sports Med 2009;43:159-62.

5 Neal BS, Griffiths IB, Dowling GJ, et al. Foot posture as a risk factor for lower limb overuse injury: a systematic review and meta-analysis. I Foot Ankle Res 2014;7:55

6 Knapik JJ, Trone DW, Tchandja J, et al. Injury-reduction effectiveness of prescribing running shoes on the basis of foot arch height: summary of military investigations. J Orthop Sports Phys Ther 2014;44:805-12.

7 Knapik JJ, Brosch LC, Venuto M, et al. Effect on injuries of assigning shoes based on foot shape in air force basic training. Am J Prev Med 2010:38:S197-211.
8 Knapik JJ, Trone DW, Swedler DI, et al. Injury reduction effectiveness of assigning running shoes based on plantar shape in Marine Corps basic training. Am I Sports Med 2010;38:1759-67.

9 Ryan MB, Valiant GA, McDonald K, et al. The effect of three different levels of footwear stability on pain outcomes in women runners: a randomised control trial. Br J Sports Med 2011;45:715-21.

10 Nigg BM, Baltich J, Hoerzer $S$, et al. Running shoes and running injuries: mythbusting and a proposal for two new paradigms: 'preferred movement path' and 'comfort filter'. Br J Sports Med 2015;49:1290-4.

11 Nielsen RO, Buist I, Parner ET, et al. Foot pronation is not associated with increased injury risk in novice runners wearing a neutral shoe: a 1-year prospective cohort study. Br I Sports Med 2014;48:440-7.

12 Moher D, Hopewell S, Schulz KF, et al. CONSORT 2010 explanation and elaboration: updated guidelines for reporting parallel group randomised trials. BMJ 2010;340:c869.

13 Keenan AM, Redmond AC, Horton M, et al. The Foot Posture Index: Rasch analysis of a novel, foot-specific outcome measure. Arch Phys Med Rehabil 2007;88:88-93.

14 Redmond AC, Crosbie J, Ouvrier RA. Development and validation of a novel rating system for scoring standing foot posture: the Foot Posture Index. Clin Biomech (Bristol, Avon) 2006;21:89-98.

15 Redmond AC, Crane YZ, Menz HB. Normative values for the Foot Posture Index. J Foot Ankle Res 2008;1:6.

16 van Gent RN, Siem D, van Middelkoop M, et al. Incidence and determinants of lower extremity running injuries in long distance runners: a systematic review. $\mathrm{Br} J$ Sports Med 2007;41:469-80; discussion 80.

17 Malisoux L, Frisch A, Urhausen A, et al. Monitoring of sport participation and injury risk in young athletes. J Sci Med Sport 2013;16:504-8.

18 Theisen D, Malisoux L, Genin J, et al. Influence of midsole hardness of standard cushioned shoes on running-related injury risk. Br J Sports Med 2014;48:371-6.

19 Malisoux L, Ramesh J, Mann R, et al. Can parallel use of different running shoes decrease running-related injury risk? Scand J Med Sci Sports 2015;25:110-15.

20 Foster C. Monitoring training in athletes with reference to overtraining syndrome. Med Sci Sports Exerc 1998:30:1164-8

21 Malisoux L, Frisch A, Urhausen A, et al. Injury incidence in a sports school during a 3-year follow-up. Knee Surg Sports Traumatol Arthrosc 2013;21:2895-900.

22 Fuller CW, Ekstrand J, Junge $A$, et al. Consensus statement on injury definitions and data collection procedures in studies of football (soccer) injuries. Br I Sports Med 2006;40:193-201.

23 Timpka T, Alonso JM, Jacobsson J, et al. Injury and illness definitions and data collection procedures for use in epidemiological studies in Athletics (track and field): consensus statement. Br J Sports Med 2014;48:483-90.

24 Peduzzi P, Concato J, Feinstein AR, et al. Importance of events per independent variable in proportional hazards regression analysis. II. Accuracy and precision of regression estimates. I Clin Epidemiol 1995;48:1503-10.

$25 \mathrm{Knol} \mathrm{MJ}$, VanderWeele TJ. Recommendations for presenting analyses of effect modification and interaction. Int J Epidemiol 2012;41:514-20.

26 Malisoux L, Nielsen RO, Urhausen A, et al. A step towards understanding the mechanisms of running-related injuries. J Sci Med Sport 2015;18:523-8.

27 Videbaek S, Bueno AM, Nielsen RO, et al. Incidence of running-related injuries per $1000 \mathrm{~h}$ of running in different types of runners: a systematic review and meta-analysis. Sports Med 2015;45:1017-26.

28 O'Leary K, Vorpahl KA, Heiderscheit B. Effect of cushioned insoles on impact forces during running. J Am Podiatr Med Assoc 2008;98:36-41.

29 De Wit $B$, De Clercq $D$, Lenoir $M$. The effect of varying midsole hardness on impact forces and foot motion during foot contact in running. J Appl Biomech 1995;11: $395-406$

30 Shorten M, Mientjes M. The 'heel impact' force peak during running is neither 'heel' nor 'impact' and does not quantify shoe cushioning effects. Footwear Sci 2011:3:41-58.

31 Cheung RT, Chung RC, Ng GY. Efficacies of different external controls for excessive foot pronation: a meta-analysis. Br I Sports Med 2011;45:743-51. 